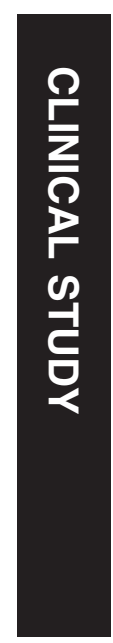

${ }^{1}$ Department of Ophthalmology, Kangdong Sacred Heart Hospital, Hallym University College of Medicine, Seoul, Korea

${ }^{2}$ Department of Ophthalmology, Kangbuk Samsung Hospital, Sungkyunkwan University School of Medicine, Seoul, Korea

${ }^{3}$ Department of Ophthalmology, Seoul National University College of Medicine, Seoul, Korea

${ }^{4}$ Department of Ophthalmology, Severence Hospital, Yonsei University College of Medicine, Seoul, Korea

${ }^{5}$ Department of Ophthalmology Seoul National University Bundang Hospital, Seoul National University College of Medicine, Seongnam, Korea

Correspondence:

JM Kim, Department of Ophthalmology, Kangbuk Samsung Hospital, Sungkyunkwan University College of Medicine, 108 Pyoung-dong, Jongro-gu, Seoul 110-746, Korea.

Tel: + 8222001 2257;

Fax: + 8222001 2262;

E-mail: kjoonmo@dreamwiz. com

${ }^{6}$ Group members are listed in the Appendix.

Received: 13 December 2011 Accepted in revised form: 5

August 2013

Published online:

13 September 2013

\section{Refractive errors in a rural Korean adult population: the Namil Study}

YC Yoo ${ }^{1}, \mathrm{JM} \mathrm{Kim}^{2}, \mathrm{KH}$ Park $^{3}, \mathrm{CY} \mathrm{Kim}^{4}$ and T-W Kim ${ }^{5}$ for the Namil Study Group, Korean Glaucoma Society ${ }^{6}$

\begin{abstract}
Purpose To assess the prevalence of refractive errors, including myopia, high myopia, hyperopia, astigmatism, and anisometropia, in rural adult Koreans. Methods We identified 2027 residents aged 40 years or older in Namil-myeon, a rural town in central South Korea. Of 1928 eligible residents, 1532 subjects $\mathbf{( 7 9 . 5 \% )}$ participated. Each subject underwent screening examinations including autorefractometry, corneal curvature measurement, and best-corrected visual acuity.
\end{abstract}

Results Data from 1215 phakic right eyes were analyzed. The prevalence of myopia (spherical equivalent (SE) $<-0.5$ diopters (D)) was $20.5 \%$ (95\% confidence interval (CI): $18.2-22.8 \%$ ), of high myopia (SE $<-6.0 \mathrm{D})$ was $1.0 \%(95 \%$ CI: $0.4-1.5 \%$ ), of hyperopia (SE $>+0.5 \mathrm{D})$ was 41.8\% (95\% CI: $38.9-44.4 \%)$, of astigmatism (cylinder $<-0.5 \mathrm{D})$ was $63.7 \%$ (95\% CI: $61.0-66.4 \%$ ), and of anisometropia (difference in SE between eyes >1.0 D) was $13.8 \%(95 \% \mathrm{CI}$ : $11.9-15.8 \%)$. Myopia prevalence decreased with age and tended to transition into hyperopia with age up to $60-69$ years. In subjects older than this, the trend in SE refractive errors reversed with age. The prevalence of astigmatism and anisometropia increased consistently with age. The refractive status was not significantly different between males and females.

Conclusions The prevalence of myopia and hyperopia in rural adult Koreans was similar to that of rural Chinese. The prevalence of high myopia was lower in this Korean sample than in other East Asian populations, and astigmatism was the most frequently occurring refractive error.

Eye (2013) 27, 1368-1375; doi:10.1038/eye.2013.195; published online 13 September 2013

Keywords: refractive error; prevalence; myopia; hyperopia; astigmatism; anisometropia
Introduction

Although most refractive errors can be corrected with glasses, contact lenses, or refractive surgery, 153 million people are estimated to experience visual impairment due to uncorrected refractive errors (ie, people presenting with a visual acuity $<6 / 18$ in the better eye, excluding presbyopia). ${ }^{1}$ Uncorrected refractive errors, which affect people of all ages and ethnic groups, may result in lost education and employment opportunities, lower productivity, and impaired quality of life.

Although no prevalence data are available from the World Health Organization or from any other sources representing very large populations such as groups of nations or entire countries, ${ }^{2}$ numerous studies have been undertaken on large, and presumably less biased, samples from disparate populations. ${ }^{3-13}$ Extrapolation from these data has provided clues about the distribution of refractive errors in several geographical populations. The prevalence of refractive errors varies among locally representative adult samples.

Although many data have been collected to help predict the prevalence of refractive errors in most populations, epidemiologic data for Koreans has not been previously reported. Recently, we examined refractive errors with autorefractometry in rural Korean adults who participated in the Namil Study, a population-based epidemiologic survey focused primarily on determining the prevalence of glaucoma among Korean people aged 40 years or older. The purpose of the present study was to describe the prevalence of refractive errors and their relationships with age and sex in a rural adult Korean sample. 


\section{Materials and methods}

\section{Study design}

The detailed methods of the Namil Study are described elsewhere, ${ }^{14}$ and are summarized below. The Namil Study was conducted in the Namil-myeon area in central South Korea, an inland, rural, agricultural area, between November 2007 and February 2008. All residents of Namil-myeon aged 40 years or older, identified using the resident registration of town inhabitants maintained by the municipal office, were encouraged to participate in an epidemiological survey to determine the prevalence of glaucoma. Notices addressed to all residents encouraged participation in the study. The study protocol adhered to the tenets of the Declaration of Helsinki and the municipal law of the Province of Chungcheonganm-do and was approved by the ethics committee of Chungnam National University Hospital and registered on the website Clinical Trials.gov (registration number:

NVT00727168). Written informed consent was obtained from all participants.

During the glaucoma screening examinations, all participants were interviewed regarding their medical history of ocular or systemic diseases and underwent measurements of non-cycloplegic refraction and corneal curvature with an autorefractometer (KR-8800, Topcon, Tokyo, Japan). The refractive error was measured in 0.25-diopter (D) increments, and the cylinder was recorded in a negative form. If the autorefractometer did not generate valid readings, the measurement was considered to have failed. The average of three measurements was recorded. The intra-observer repeatability as presented by intraclass correlation coefficient was 0.992 (95\% confidence interval (CI): 0.986 - 0.996). Visual acuity was measured using Han's vision chart (Han Medical, Seoul, Korea) at a distance of $5 \mathrm{~m}$. In participants presenting with a visual acuity of $<0.8$ in either eye, corrected visual acuity was assessed using previously measured objective autorefraction data. Additionally, ocular examinations were performed, including slit-lamp examinations with nuclear sclerosis grading $(\mathrm{N} 1-6)$ of the lens according to the Lens Opacities Classification System III, ${ }^{15}$ intraocular pressure measurement using Goldmann applanation tonometry, and fundus photography (TRC-NW200, Topcon).

\section{Definitions}

The data from the autorefractometer were converted into spherical equivalents (SEs), which are equal to the algebraic sum of the value of the sphere and half the cylindrical value. Because SE values were strongly correlated (concordance correlation coefficient $r_{\mathrm{c}}=0.818$ and $95 \% \mathrm{CI}=(0.798-0.836))$ between the right and left eyes $(n=1167)$, refraction data for the right eyes were arbitrarily chosen to define myopia, high myopia, hyperopia, and refractive astigmatism. Myopia was defined as an SE $<-0.5 \mathrm{D}$, and high myopia was further defined as an SE <-6.0 D; hyperopia was defined as an $\mathrm{SE}>+0.5 \mathrm{D}$, and anisometropia was defined as a difference of $>1.0 \mathrm{D}$ in the SEs of the right and left eyes. Refractive astigmatism was defined as a negative cylindrical value $<-0.5$ or $-1.0 \mathrm{D}$ without reference to the axis. These definitions were chosen in order to compare our data with those published in the literature.

\section{Statistical analysis}

For statistical analysis, each refractive error was coded as a separate binary variable in terms of presence or absence; for example, myopic versus nonmyopic. Logistic regression was used to determine the association between the prevalence of refractive errors and age or sex. Statistical analyses were performed using SPSS software version 15.0 (SPSS Inc., Chicago, IL, USA) and $P$-values $<0.05$ were considered significant.

\section{Results}

Of the 3104 residents registered at the municipal office in 2006, there were 2027 residents aged $\geq 40$ years (1105 women and $922 \mathrm{men}$ ). At the end of the screening period (28 February 2008), 1928 residents were eligible; 20 had died, and 79 had moved from the Namil area or could not be located in Namil-myeon. Among these, 1532 subjects (887 women and 645 men) participated in the screening examination for a participation rate of $79.5 \%$. The participation rates for each age group are shown in Table 1 . The participation rates were generally greater in the older age groups. The mean age of the 396 nonparticipants $(62.5 \pm 14.0$ years, mean \pm standard deviation) was younger than that of the participants $(64.1 \pm 11.5$ years) according to an independent $t$-test $(P=0.03)$.

With regard to the right eyes of the 1532 examined subjects, 134 had undergone prior cataract surgery with or without intraocular lens placement, 138 had inappropriate refractive data due to pterygium, corneal opacities, or severe dense cataract or other media opacities, 5 had prostheses or severe anomalies of anterior or posterior segments due to ocular disease or trauma, 3 had congenital strabismus, and 37 had no results or unreliable results from the autorefractometer. This left 1215 phakic subjects with appropriate refractive data for their right eyes for further analysis. Details of the enrollment and dropout through the process of the study are displayed in Figure 1. The 317 subjects excluded from our analysis were older (independent $t$-test, $P<0.001$ ) 
Table 1 Participation rates for each age group

\begin{tabular}{|c|c|c|c|c|c|c|c|c|c|}
\hline \multirow[t]{2}{*}{ Age (years) } & \multicolumn{3}{|c|}{ Men } & \multicolumn{3}{|c|}{ Women } & \multicolumn{3}{|c|}{ Men and Women } \\
\hline & Residents ( $n$ ) & Participants ( $n$ ) & Rate (\%) & Residents (n) & Participants ( $n$ ) & Rate (\%) & Residents (n) & Participants ( $n$ ) & Rate (\%) \\
\hline $40-49$ & 171 & 101 & 59.1 & 152 & 110 & 72.4 & 323 & 211 & 65.3 \\
\hline $50-59$ & 211 & 160 & 75.8 & 196 & 161 & 82.1 & 407 & 321 & 78.9 \\
\hline $60-69$ & 211 & 173 & 81.9 & 304 & 257 & 84.5 & 515 & 430 & 83.5 \\
\hline $70-79$ & 203 & 170 & 83.7 & 319 & 276 & 87.1 & 522 & 446 & 85.4 \\
\hline$\geq 80$ & 56 & 41 & 73.2 & 105 & 83 & 79.0 & 161 & 124 & 77.0 \\
\hline Total & 852 & 645 & 75.7 & 1076 & 887 & 82.4 & 1928 & 1532 & 79.5 \\
\hline
\end{tabular}

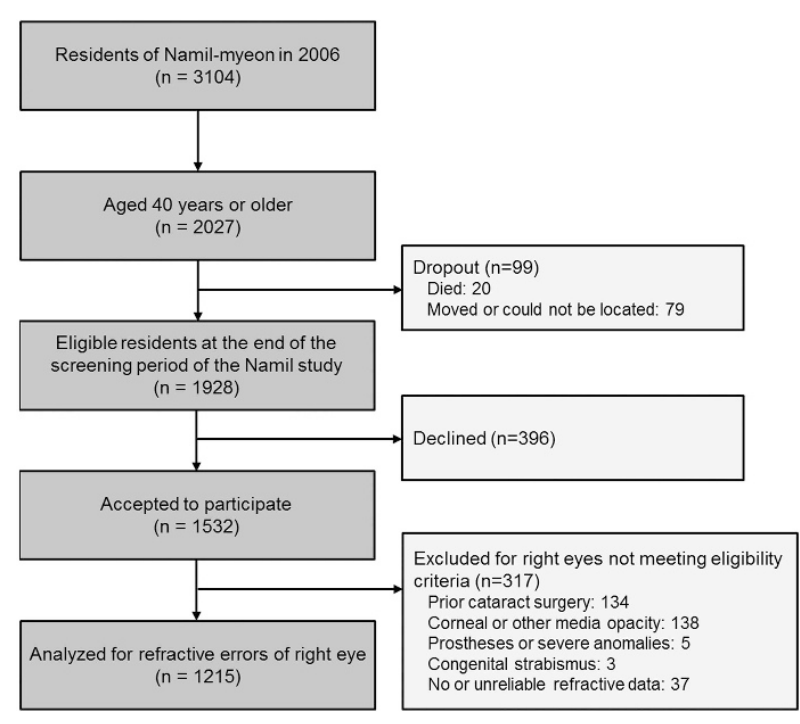

Figure 1 Flow diagram of the enrollment and dropout.

and included more females (chi-square test, $P=0.001$ ) than the group of accepted subjects. We were able to analyze anisometropia after excluding an additional 48 subjects whose refractive data for their left eyes were not appropriate for analysis for similar reasons to those mentioned above. The mean age of the 1215 remaining subjects was $62.19 \pm 11.18$ years (range, 40 - 99 years), and 675 of the subjects (55.6\%) were female. Female subjects ( $62.95 \pm 11.06$ years) tended to be older than male subjects (61.24 \pm 11.27 years) (independent $t$-test, $P=0.004)$.

In our study sample, the mean refractive error, expressed in terms of $\mathrm{SE}$, was $+0.20 \pm 1.93 \mathrm{D}$ (median: $+0.25 \mathrm{D}$; range: -22.38 to $+5.88 \mathrm{D}$ ). Figure 2 shows the distribution of SE refractive errors in the study sample. The distribution was slightly skewed toward hyperopia (skewness: $-4.26 \pm 0.07$ ) and had a high peak and thin tail (kurtosis: $38.03 \pm 0.14$ ). The crude prevalence of refractive errors is summarized in Table 2. In a binary logistic regression analysis model using age and sex as variables, both myopia (SE $<-0.5 \mathrm{D})$ and hyperopia
$(\mathrm{SE}>+0.5 \mathrm{D})$ were significantly associated with age (odds ratio $(\mathrm{OR})=0.974(95 \% \mathrm{CI}$ : $0.961-0.986)$ and 1.085 (95\% CI: $1.071-1.098)$, respectively; $P<0.001)$. The myopic refractive error most prevalent in the youngest age group decreased and tended to transition into hyperopic refractive error with age up to the $60-69$ year-old age group. In subjects older than the 60-69year-old age group, the trend of SE refractive errors reversed; the prevalence of myopia increased and that of hyperopia decreased with age up to over than 80 years. Female sex was not associated with the prevalence of myopia (OR $=1.229 ; 95 \% \mathrm{CI}: 0.924-1.635 ; P=0.156)$ and hyperopia ( $\mathrm{OR}=1.277 ; 95 \% \mathrm{CI}$ : $0.994-1.642 ; P=0.056)$. However, men tended to have more myopic refractive errors in the oldest age group (chi-square test, $P=0.02$ ). The prevalence of high myopia (SE $<-6.0 \mathrm{D}$ ) was associated with age (OR $=0.916$; $95 \%$ CI: $0.865-0.970$; $P=0.003)$ while that was not associated with female sex (OR $=3.128$; 95\% CI: $0.850-11.509 ; P=0.086$ ).

The mean astigmatic refractive error in the study sample was $-0.98 \pm 0.77 \mathrm{D}$ (median: $0.75 \mathrm{D}$; range: $-5.5-0 \mathrm{D})$. The frequency distribution of refractive astigmatism is shown in Figure 2. Refractive astigmatism did not follow a Gaussian distribution curve but was instead skewed rightward (skewness: $1.36 \pm 0.07$ ). Most subjects $(63.7 \%)$ had refractive astigmatism of $>-0.5 \mathrm{D}$ and 423 subjects (34.8\%) had refractive astigmatism of $>-1.0 \mathrm{D}$. In a binary logistic regression analysis model using age and sex, the prevalence of refractive astigmatism (cylinder $<-0.5 \mathrm{D}$ ) varied significantly by age $(\mathrm{OR}=1.062 ; 95 \% \mathrm{CI}: 1.050-1.704 ; P<0.001)$.

However, sex was not associated with the prevalence of refractive astigmatism $(\mathrm{OR}=1.138$; $95 \%$ CI: $0.889-1.457$; $P=0.304)$.

Among 1167 subjects in whom both eyes were eligible, the mean absolute difference in SE between the right and left eyes was $0.63 \pm 1.07 \mathrm{D}$ (median: 0.38 D; range: $0-20.38$ D). As shown in Figure 2, the distribution curve of anisometropia did not follow a Gaussian distribution, but was instead skewed to the right (skewness: $8.35 \pm 0.07$ ) with a high peak and thin 


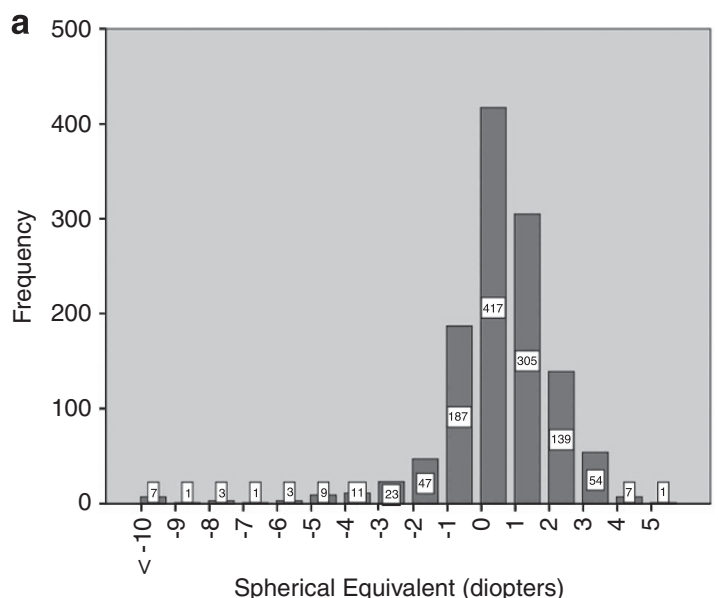

Spherical Equivalent (diopters) b

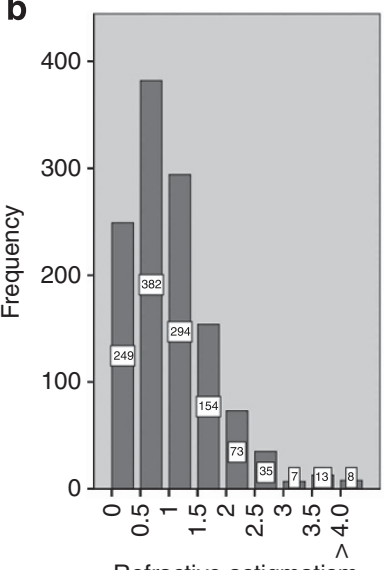

Refractive astigmatism (diopters) c

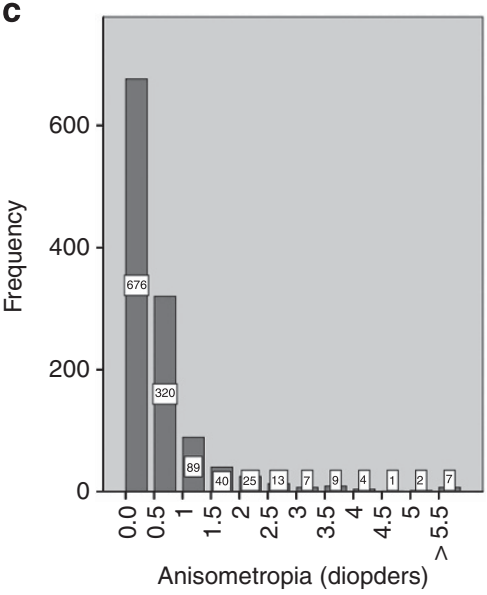

Figure 2 Histograms showing the frequency distributions of spherical equivalent (a) and astigmatic refractive error (b) in the right eyes of 1215 subjects and anisometropia (c) in 1167 subjects.

Table 2 Prevalence of refractive errors in the study sample by age and sex group

\begin{tabular}{|c|c|c|c|c|c|c|c|}
\hline $\begin{array}{l}\text { Age } \\
\text { (years) }\end{array}$ & $n$ & $\begin{array}{c}\text { Emmetropia } \\
(-0.5 \text { to }+0.5 \mathrm{D})\end{array}$ & $\begin{array}{c}\text { Myopia } \\
(<-0.5 \mathrm{D})\end{array}$ & $\begin{array}{l}\text { High myopia } \\
(<-6.0 \mathrm{D})\end{array}$ & $\begin{array}{l}\text { Hyperopia } \\
(>+0.5 \mathrm{D})\end{array}$ & $\begin{array}{c}\text { Refractive astigmatism } \\
\qquad(<-0.5 \mathrm{D})\end{array}$ & $\begin{array}{l}\text { Anisometropia } \\
(>1.0 \mathrm{D})\end{array}$ \\
\hline \multicolumn{8}{|l|}{ Men } \\
\hline $40-49$ & 96 & $66.7(57.2-76.1)$ & $29.2(20.1-38.3)$ & $1.0(0-5.0)$ & $4.2(0.0-8.2)$ & $32.3(22.9-41.6)$ & $6.3(1.4-11.2)$ \\
\hline $50-59$ & 145 & $56.6(48.5-64.6)$ & $17.9(11.7-24.2)$ & $0.7(0-2.1)$ & $25.5(18.4-32.6)$ & $51.0(42.9-59.2)$ & $5.5(1.8-9.2)$ \\
\hline $60-69$ & 149 & $35.6(27.9-43.3)$ & $12.1(6.8-17.3)$ & 0 (NA) & $52.3(44.3-60.4)$ & $69.1(61.7-76.5)$ & $15.1(9.3-20.9)$ \\
\hline $70-79$ & 124 & $27.4(19.6-35.3)$ & $13.7(7.7-19.8)$ & 0 (NA) & $58.9(50.2-67.5)$ & $79.8(72.8-86.9)$ & $34.2(25.7-42.7)$ \\
\hline$>80$ & 26 & $7.7(0.0-17.9)$ & $53.8(34.7-73.0)$ & 0 (NA) & $38.5(19.8-57.2)$ & 84.6 (70.7-98.5) & $50.0(30.0-70.0)$ \\
\hline All & 540 & $43.5(39.3-47.7)$ & $19.1(15.8-22.4)$ & $0.4(0-1.3)$ & $37.4(33.0-41.1)$ & $60.9(56.8-65.0)$ & $16.8(13.6-20.0)$ \\
\hline \multicolumn{8}{|l|}{ Women } \\
\hline $40-49$ & 102 & $55.9(46.2-65.5)$ & $42.2(32.6-51.7)$ & $2.9(0-6.2)$ & $2.0(0-4.7)$ & $46.1(36.4-55.8)$ & $8.0(2.7-13.3)$ \\
\hline $50-59$ & 143 & $46.9(38.7-55.0)$ & $23.8(16.8-30.8)$ & $2.8(0.1-5.5)$ & $29.4(21.9-36.8)$ & $56.6(48.5-64.8)$ & $6.3(2.3-10.3)$ \\
\hline $60-69$ & 222 & $22.5(17.0-28.0)$ & $14.0(9.4-18.5)$ & $0.9(0-2.1)$ & $63.5(57.2-69.8)$ & $68.5(62.4-74.6)$ & $16.4(11.5-21.3)$ \\
\hline $70-79$ & 171 & $24.0(17.6-30.4)$ & $17.5(11.8-23.2)$ & $0.6(0-1.8)$ & $58.5(51.1-65.9)$ & $76.7(70.3-83.0)$ & $25.0(18.5-31.5)$ \\
\hline$>80$ & 37 & $21.6(8.4-34.9)$ & $21.6(8.4-34.9)$ & 0 (NA) & $56.8(40.8-72.7)$ & $91.9(83.1-100.0)$ & $39.4(22.7-56.1)$ \\
\hline All & 675 & $33.0(29.5-36.6)$ & $21.6(18.5-24.7)$ & $1.5(0.6-2.4)$ & $45.3(41.6-49.1)$ & $65.9(62.4-69.5)$ & $16.3(13.5-19.1)$ \\
\hline \multicolumn{8}{|c|}{ Men and women } \\
\hline $40-49$ & 198 & $62.1(55.4-68.9)$ & $35.9(29.2-42.5)$ & $2.0(0.3-4.7)$ & $3.0(0.6-5.4)$ & $39.4(32.6-46.2)$ & $7.2(3.6-10.8)$ \\
\hline $50-59$ & 288 & $51.7(46.0-57.5)$ & $20.8(16.1-25.5)$ & $1.7(0.2-3.2)$ & $27.4(22.3-32.6)$ & $53.8(48.1-59.6)$ & $5.9(3.2-8.6)$ \\
\hline $60-69$ & 371 & $27.8(23.2-32.3)$ & $13.2(9.8-16.7)$ & $0.5(0.0-1.2)$ & $59.0(54.0-64.0)$ & $68.7(64.0-73.5)$ & $15.9(12.1-19.7)$ \\
\hline $70-79$ & 295 & $25.4(20.5-30.4)$ & $15.9(11.8-20.1)$ & $0.3(0.0-0.9)$ & $58.6(53.0-64.3)$ & $78.0(73.2-82.7)$ & $28.8(23.6-34.0)$ \\
\hline$>80$ & 63 & $15.9(6.8-24.9)$ & $34.9(23.1-46.7)$ & 0.0 (NA) & $49.2(36.9-61.6)$ & $88.9(81.1-96.6)$ & $43.9(31.0-56.8)$ \\
\hline All & 1215 & $37.7(35.0-40.4)$ & $20.5(18.2-22.8)$ & $1.0(0.5-1.7)$ & $41.8(39.0-44.6)$ & $63.7(61.0-66.4)$ & $16.5(14.4-18.6)$ \\
\hline
\end{tabular}

D, diopters.

Prevalence (\%) is shown with 95\% confidence intervals in parentheses.

Prevalence of anisometropia was calculated after excluding 48 subjects whose refractive data for left eyes were not appropriate for analysis $(n=1167)$.

tail (kurtosis: $116.28 \pm 0.14)$. One hundred and sixty-five subjects $(13.8 \%)$ had anisometropia of $>1.0 \mathrm{D}$. The prevalence of anisometropia (SE $>1.0 \mathrm{D}$ ) had a tendency to increase with age ( $\mathrm{OR}=1.092 ; 95 \% \mathrm{CI}$ : $1.072-1.112 ; P<0.001)$. Sex was not associated with the prevalence of anisometropia ( $\mathrm{OR}=0.759 ; 95 \% \mathrm{CI}$ : $0.536-1.075 ; P=0.121)$.

\section{Discussion}

This report is the first large-scale, population-based, cross-sectional survey of refractive errors in adult Koreans. Consistent with the findings of previous large-scale epidemiologic surveys, ${ }^{5,11}$ the distribution of the SE refractive statuses of rural adult Koreans 
demonstrated positive kurtosis and negative skewness (ie, positive mean values and prolongation of the myopic limb). When our results were compared with the overall crude prevalence of refractive errors published in previous population-based surveys, which were undertaken in various races and had similar age distributions and refractive error definitions to those of our study (Table 3), the prevalence of refractive errors in the Korean rural town studied here was slightly different from those found in samples of other races. ${ }^{3-13}$

Although the prevalence of myopia varies across studies with no specific pattern observed by ancestral origin in adult populations, ${ }^{16}$ myopia is particularly prevalent in East Asia, especially among the Japanese. ${ }^{11}$ The prevalence of myopia (SE $<-0.5 \mathrm{D}$ ) in rural adult Koreans was $20.5 \%$. This was similar to the prevalence found in population-based studies of rural Chinese $(18.8 \%),{ }^{10,13}$ but lower than that observed in populationbased studies of urban Chinese $(32.3 \%),{ }^{12}$ Singapore Chinese $(35.0 \%)^{7}$ and Japanese $(41.8 \%){ }^{11}$ and higher than that found in a Mongolian population-based sample $(17.2 \%) .{ }^{9}$ The prevalence of hyperopia (SE $\left.>+0.5 \mathrm{D}\right)$ in our study sample was $41.8 \%$. This was higher than the prevalence figures reported in rural Chinese $(20.0-23.1 \%),{ }^{10,13}$ Indonesians $(32.1 \%),{ }^{8}$ Mongolians $(32.9 \%)^{9}$ and Japanese $(27.9 \%),{ }^{11}$ and similar to those of other East Asian samples including Singapore Chinese $(35.9 \%)^{7}$ and urban Chinese $(40.0 \%) .{ }^{12}$ The prevalence of high myopia (SE $<-5.0 \mathrm{D}$ or $-6.0 \mathrm{D}$ ) in our study sample was $1.2 \%$ or $1.0 \%$, respectively. This was lower than that reported in population-based studies of other East Asians (1.4-6.9\%). ${ }^{7-13}$

A general pattern of changes in refractive errors by age group has been observed in previous large-scale epidemiologic surveys. ${ }^{7,8,11,12}$ Our results correspond with the results of these studies, which reported that the prevalence of myopia generally follows a bimodal pattern in adults, initially declining with age and then increasing in the higher age groups. In contrast to myopia, the prevalence of hyperopia in our study sample generally increased with age and then decreased in people older than 70 years. Although the exact reason for these age-based prevalence patterns of hyperopia and myopia is still controversial, several theories have been postulated to explain this observation. The prevalence of myopia, which is believed to develop between 6 and 14 years of age, remains relatively constant thereafter and tends to decline after middle age. ${ }^{17}$ This decline can be attributed to previous findings that older people have shorter mean axial lengths compared with younger people. ${ }^{7}$ The shortening of axial length with age can be explained by a cohort effect, especially in East Asian populations, where myopia prevalence rates of over $32 \%$ in children of age $5-15$ years have been reported. ${ }^{18-20}$ Factors such as increasing urbanization and more intensive nearwork demands have been thought to contribute to the high myopia rates in younger age groups. However, it is also possible that the changes occur as a result of longitudinal changes due to aging. Myopic shift from the age of 70 years and onward is thought to be related, at least in part, to the development of lens nucleosclerosis. In our study, the degree of nuclear sclerosis of the lens increased with age $(r=0.470$, $P<0.01)$ and this trend was apparent at age groups after the $70-79$-year-old age group (independent $t$-test, $P<0.001)$. Also, the degree of nucleosclerosis was associated with myopia in a logistic regression analysis using age, sex, and nucleosclerosis as variables $(\mathrm{OR}=1.360 ; 95 \% \mathrm{CI}: 1.198-1.574 ; P<0.01)$. Several

Table 3 Reported prevalence figures of refractive errors in previous population-based studies

\begin{tabular}{|c|c|c|c|c|c|c|c|c|}
\hline Study & Sample & $n$ & $\begin{array}{c}\text { Age } \\
\text { (years) }\end{array}$ & $\begin{array}{c}\text { Myopia } \\
(<-0.5 \mathrm{D}) \\
(\%)\end{array}$ & $\begin{array}{c}\text { High myopia } \\
(<-6.0 \mathrm{D}) \\
(\%)\end{array}$ & $\begin{array}{c}\text { Hyperopia } \\
(>+0.5 \mathrm{D}) \\
(\%)\end{array}$ & $\begin{array}{c}\text { Astigmatism } \\
(<-0.5 D) \\
(\%)\end{array}$ & $\begin{array}{l}\text { Anisometropia } \\
(>1.0 D)(\%)\end{array}$ \\
\hline Beijing Eye Study & Chinese & 4319 & $\geq 40$ & 21.8 & 2.6 & 20.0 & - & - \\
\hline Handan Eye Study & Chinese & 5251 & $\geq 40$ & 18.8 & 1.4 & 23.1 & - & - \\
\hline Tanjong Pagar Study & Singapore Chinese & 1113 & $\geq 40$ & 35.0 & $6.9^{\mathrm{a}}$ & 35.9 & 43.9 & 20.0 \\
\hline Liwan Eye Study & Chinese & 1269 & $\geq 50$ & 32.3 & - & 40.0 & $48.3^{\mathrm{b}}$ & - \\
\hline Sumatra & Indonesian & 358 & $\geq 40$ & 34.1 & 1.7 & 32.1 & 59.8 & 24.3 \\
\hline Mongolia & Mongolian & 1617 & $\geq 40$ & 17.2 & $2.7^{\mathrm{a}}$ & 32.9 & 40.9 & 10.7 \\
\hline Tajimi Study & Japanese & 2829 & $\geq 40$ & 41.8 & 5.5 & 27.9 & 54.0 & 15.1 \\
\hline Beaver Dam Eye Study & European-American & 4275 & $\geq 43$ & 26.2 & - & 49.0 & - & - \\
\hline Blue Mountain Eye Study & European-American & 3174 & $\geq 49$ & 15.5 & - & 56.6 & 37.0 & 14.1 \\
\hline Baltimore Eye Study & European-American & 2659 & $\geq 40$ & 24.1 & $1.9^{\mathrm{a}}$ & 47.4 & - & - \\
\hline Baltimore Eye Study & African-American & 2200 & $\geq 40$ & 20.9 & $0.9^{\mathrm{a}}$ & 38.1 & - & - \\
\hline Barbados & Afro-Caribbean & 4036 & $\geq 40$ & 21.9 & - & 46.9 & - & - \\
\hline
\end{tabular}

D, diopters.

${ }^{a}$ High myopia defined as spherical equivalents $<-5.0 \mathrm{D}$.

${ }^{\mathrm{b}}$ Refractive astigmatism defined as $<-0.75 \mathrm{D}$. 
studies have demonstrated an association between nuclear cataracts and myopia..$^{9,11-13}$ It has been suggested that this may be due to an increase in the density, and hence the refractive index, of the lens with age.

Figure 3 summarizes the age-specific rates of myopia and hyperopia in East Asian adults, as derived from population-based studies with available published data based on similar definitions of refractive error and age categories. In people aged $40-49$ years, who are less often affected by nuclear cataracts, the rates of myopia are remarkably different among East Asian populations. The prevalence of myopia was highest in Japanese living in the city of Tajimi and lowest in rural Mongolians. Interestingly, the differences in myopia prevalence disappeared in the middle-age groups. The prevalence of myopia in rural adult Koreans was similar to that of rural Chinese and lower than that of urban Chinese. However, in the youngest age group, the prevalence of hyperopia was not remarkably different among East Asian populations except for rural Mongolians. A shift toward hyperopia in the middle-age groups and an increase in myopia in the oldest age groups was found in all study populations.

The crude prevalence of astigmatic refractive errors (cylinder $<-0.5 \mathrm{D}$ ) in our study sample was 63.7\%, which is the highest reported value among the previously reported population-based studies (Table 3). The frequency of clinically significant reactive astigmatism (cylinder $<-1.0 \mathrm{D}$ ) was $34.8 \%$ (95\% CI: $32.1-37.5 \%)$. These results may be due in part to our measurement techniques in assessing refractive errors. We measured astigmatic refractive errors with an autorefractometer and did not adjust it using subjective refraction. There was a significant age-dependent increase in the prevalence of astigmatic refractive errors in our study. This result is consistent with the results reported in previous epidemiologic surveys.

The frequency of anisometropia ( $>1.0 \mathrm{D}$ ) in rural adult Koreans was similar to the frequencies observed in epidemiologic surveys of Japanese $(15.1 \%),{ }^{11}$ Mongolians $(10.7 \%),{ }^{9}$ and subjects of European descent $(14.1 \%),{ }^{5}$ and lower than those observed in Singapore Chinese $(20.0 \%)^{7}$ and Indonesians (24.3\%). ${ }^{8}$ The frequency was strongly associated with age, a result that is consistent with the results of previous studies. ${ }^{7-13}$ Both astigmatism and anisometropia demonstrated a monotonic increase in prevalence with age.

The association of sex with refractive errors has not been well established. Some studies have reported that the prevalence of myopia is higher in men than in women. ${ }^{5,6}$ In other studies, however, this trend was not observed $^{4}$ or was even reversed between sexes. ${ }^{3,10}$ Our study demonstrated that there are no differences in sexes with regard to the overall rates of myopia and other refractive errors.

Several potential limitations of our study should be considered when interpreting our results. First, our study sample was drawn from a rural Korean population that had a significantly different age structure than the general Korean population. Second, we did not take into account the environmental factors that may have affected refractive errors, especially myopia. Differences in education, housing, and income may restrict the standardization of our results to the census population and limit comparisons of our results with those from other populations. Third, our study was not a longitudinal epidemiologic survey but rather a crosssectional study. Considering that the age-related changes in refractive errors revealed in our cross-sectional study may be due to both real biological aging effects and cohort effects, a longitudinal epidemiologic survey may be needed to confirm our results. The Beaver Dam Eye Study, ${ }^{21}$ which provided the only available report of age-related longitudinal changes in refractive error over a 10-year period in a population-based sample, found that both biological and cohort effects on refractive error appeared to be important in determining changes in the age-specific prevalence of refractive errors over time. Cohort effects were demonstrated by substantial changes in mean SE. Further longitudinal data are needed to evaluate whether similar cohort effects occurred in our population. Fourth, our data do not address the prevalence of refractive errors in children and younger adults. It has been reported that children have high rates of myopia. Therefore, the lack of
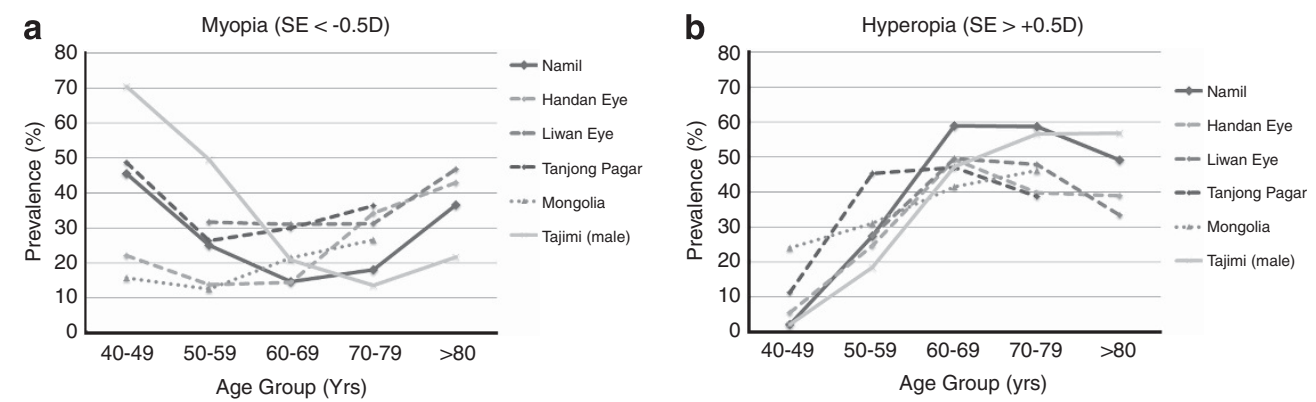

Figure 3 Prevalence of myopia (a) and hyperopia (b) in various population-based epidemiologic surveys of East Asians. 
refraction data for this age group may be an important gap in our understanding of the prevalence of refractive errors. Fifth, the response to the screening examination was $79.5 \%$. Although the overall participation rate was high, this rate was lower among younger people than among older people (Table 1). This would potentially underestimate the prevalence of myopia in younger age groups. In addition, participants excluded from the analyses due to cataract surgery were older and included more females, this would also over- or underestimate the prevalence of refractive error. Lastly, the use of noncycloplegic refraction to calculate SE may have artificially induced greater degrees of myopia due to some amount of accommodation, especially in younger subjects.

In summary, the present report from the Namil Study has documented the refractive status of a rural adult Korean population in detail. Consistent with previous studies, our results demonstrated that the prevalence of myopia and hyperopia in rural adult Koreans changes with age according to a bimodal pattern. Regarding other refractive errors, there was a monotonic increase in the prevalence of refractive astigmatism and anisometropia with age. Other remarkable observations of our study include the fact that hyperopia, but not myopia, was more common in women than in men and that this Korean sample had a higher prevalence of reactive astigmatism and a lower prevalence of high myopia compared with previous studies of other East Asian populations.

\section{Summary}

\section{What was known before}

- Although many data have been collected to help predict the prevalence of refractive errors in most populations, epidemiologic data for Koreans has not been previously reported.

\section{What this study adds}

- The prevalence of myopia and hyperopia in rural adult Koreans was similar to that of rural Chinese.

- The prevalence of high myopia was lower in this Korean sample than in other East Asian populations, and astigmatism was the most frequently occurring refractive error.

\section{Conflict of interest}

The authors have no proprietary or commercial interest in any of the materials discussed in the article.

\section{Acknowledgements}

This study was supported by Alcon Korea, Merck Korea, Pfizer Korea, Taejoon Pharmaceutical, Zeiss Korea, and the Korean Ophthalmological Society.

\section{Statement about conformity with author information}

The IRB approval was before the study began. The study protocol adhered to the tenets of the Declaration of Helsinki and the municipal law of the Province of Chungcheonganm-do and was approved by the ethics committee of Chungnam National University Hospital and registered on the website Clinical Trials.gov (registration number: NVT00727168). Written informed consent was obtained from all participants.

\section{Author contributions}

Design of the study (KHP, CYK, and TWK), conduct of the study (JMK, KHP, CYK, and TWK), collection, management, and analysis of the data (YCY and JMK), interpretation of the data (YCY, JMK, and KHP), preparation of manuscript (YCY), review of the manuscript (YCY and JMK).

\section{References}

1 Resnikoff S, Pascolini D, Mariotti SP, Pokharel GP. Global magnitude of visual impairment caused by uncorrected refractive errors in 2004. Bull World Health Organ 2008; 86(1): 63-70.

2 Resnikoff S, Kocur I, Etya'ale DE, Ukety TO. Vision 2020 - the right to sight. Ann Trop Med Parasitol 2008; 102(Suppl): 13-15.

3 Wang Q, Klein BE, Klein R, Moss SE. Refractive status in the beaver dam eye study. Invest Ophthalmol Vis Sci 1994; 35(13): 4344-4347.

4 Katz J, Tielsch JM, Sommer A. Prevalence and risk factors for refractive errors in an adult inner city population. Invest Ophthalmol Vis Sci 1997; 38(2): 334-340.

5 Attebo K, Ivers RQ, Mitchell P. Refractive errors in an older population: the blue mountains eye study. Ophthalmology 1999; 106(6): 1066-1072.

6 Wu SY, Nemesure B, Leske MC. Refractive errors in a black adult population: the barbados eye study. Invest Ophthalmol Vis Sci 1999; 40(10): 2179-2184.

7 Wong TY, Foster PJ, Hee J, Ng TP, Tielsch JM, Chew SJ et al. Prevalence and risk factors for refractive errors in adult Chinese in Singapore. Invest Ophthalmol Vis Sci 2000; 41(9): 2486-2494.

8 Saw SM, Gazzard G, Koh D, Farook M, Widjaja D, Lee J et al. Prevalence rates of refractive errors in Sumatra, Indonesia. Invest Ophthalmol Vis Sci 2002; 43(10): 3174-3180.

9 Wickremasinghe S, Foster PJ, Uranchimeg D, Lee PS, Devereux JG, Alsbirk PH et al. Ocular biometry and refraction in Mongolian adults. Invest Ophthalmol Vis Sci 2004; 45(3): 776-783.

$10 \mathrm{Xu} \mathrm{L}$, Li J, Cui T, Hu A, Fan G, Zhang R et al. Refractive error in urban and rural adult Chinese in Beijing. Ophthalmology 2005; 112(10): 1676-1683.

11 Sawada A, Tomidokoro A, Araie M, Iwase A, Yamamoto T. Tajimi Study Group. Refractive errors in an elderly Japanese population: the Tajimi study. Ophthalmology 2008; 115(2): 363-370; e3. 
12 He M, Huang W, Li Y, Zheng Y, Yin Q, Foster PJ. Refractive error and biometry in older Chinese adults: the Liwan eye study. Invest Ophthalmol Vis Sci 2009; 50(11): 5130-5136.

13 Liang YB, Wong TY, Sun LP, Tao QS, Wang JJ, Yang XH et al. Refractive errors in a rural Chinese adult population the handan eye study. Ophthalmology 2009; 116(11): 2119-2127.

14 Kim CS, Seong GJ, Lee NH, Song KC. Namil Study Group, Korean Glaucoma Society. Prevalence of primary openangle glaucoma in central south Korea the Namil study. Ophthalmology 2011; 118(6): 1024-1030.

15 Chylack Jr LT, Wolfe JK, Singer DM, Leske MC, Bullimore MA, Bailey IL et al. The lens opacities classification system III. the longitudinal study of cataract study group. Arch Ophthalmol 1993; 111(6): 831-836.

16 Hyman L. Myopic and hyperopic refractive error in adults: an overview. Ophthalmic Epidemiol 2007; 14(4): 192-197.

\section{Appendix}

\section{The Namil Study Group, Korean Glaucoma Society:}

Byung-Heon Ahn, MD, PhD, Department of Ophthalmology, Samsung Medical Center, Sungkyunkwan University School of Medicine

Myung Douk Ahn, MD, PhD, Department of Ophthalmology, College of Medicine, The Catholic University of Korea

Nam Ho Baek, MD, PhD, Saevit Eye Hospital

Kyu-Ryong Choi, MD, PhD, Department of Ophthalmology, Ewha Womans University School of Medicine

Seung-Joo Ha, MD, Department of Ophthalmology, Soonchunhyang University, College of Medicine Gyu-Heon Han, MD, PhD, Doctor Lee's Eye Clinic Young Jae Hong, MD, PhD, Nune Eye Hospital
17 Saw SM, Katz J, Schein OD, Chew SJ, Chan TK. Epidemiology of myopia. Epidemiol Rev 1996; 18(2): 175-187.

18 Saw SM, Tong L, Chua WH, Chia KS, Koh D, Tan DT et al. Incidence and progression of myopia in Singaporean school children. Invest Ophthalmol Vis Sci 2005; 46(1): 51-57.

19 Fan DS, Lam DS, Lam RF, Lau JT, Chong KS, Cheung EY et al. Prevalence, incidence, and progression of myopia of school children in Hong Kong. Invest Ophthalmol Vis Sci 2004; 45(4): 1071-1075.

20 Lee EK, Lee DB, Jin KH, Kim JM. The study of the correlation between axial length and refractive error in Korean children. J Korean Ophthalmol Soc 1993; 34(7): 654-660.

21 Lee KE, Klein BE, Klein R, Wong TY. Changes in refraction over 10 years in an adult population: the beaver dam eye study. Invest Ophthalmol Vis Sci 2002; 43(8): 2566-2571.

Ja-Heon Kang, MD, PhD, Department of Ophthalmology, Kyung Hee University College of Medicine

Changwon Kee, MD, PhD, Department of Ophthalmology, Samsung Medical Center,

Sungkyunkwan University School of Medicine

Hong-Seok Kee, MD, PhD, Leeyeon Eye Clinic

Chan Yun Kim, MD, PhD, Department of

Ophthalmology, Yonsei University College of Medicine

Chang-Sik Kim, MD, PhD, Department of

Ophthalmology, College of Medicine, Chungnam

National University

Hwang-Ki Kim, MD, Department of Ophthalmology, Konyang University College of Medicine, Kim's Eye Hospital

Joon-Mo Kim, MD, Department of Ophthalmology, Sungkyunkwan University School of Medicine, Kangbuk Samsung Hospital 